\title{
The Study of Inheritance and Cultural Value of Music Culture in Tang Dynasty
}

\author{
Zhang Jing \\ Xidian University, Xi’an, Shaanxi 710071
}

Keywords: Tang Dynasty; music culture; historical achievements cultural value

\begin{abstract}
Chinese civilization has a long history, and Tang Dynasty is a dazzling pearl in the long history river. Under the background of political stability and economic prosperity, the music thoughts, genre, theme of Tang presents great diversity, which possesses unparalleled cultural value for Chinese music history. This article analyzes the inheritance and achievement of music culture in Tang Dynasty from style, genre, institute, musician, instrument, music and dance record, performance and so on.

The inheritance of the traditional culture modulates the nowadays profound culture of China, and the music culture inheritance also occupies an important position. The Tang Dynasty as the summit of Chinese ancient civilization, the music development level at that time is ahead of other countries in the world. With the limited material conditions in ancient time, the inheritance of such an important historical achievement is inseparable with the inheritance concepts at that time, and the orthodox historical materials and the literati's literary theory have recorded numerous information about music. It provides a historical basis for inheritance of Tang music at modern times. This paper follows the history line and analyzes the music culture of Tang Dynasty in art achievements and cultural value. Enter the Tang Dynasty and perceive its brilliant music atmosphere.
\end{abstract}

\section{Court music---the historical achievement and cultural value of Yan music}

Yan music is also called banquet music, as the court music of Tang Dynasty, it is an important art form in Tang, with beautiful melody, magnificent air and diversified forms. In the field of world classical music, Yan music also has great influence. The Yan music is performed in the banquet of the court, which has a broad and a narrow sense of meaning; the broad sense of Yan music covers all the Han folk music and the foreign music; the Yan music in a narrow sense specially refers to the first book of nine Tang musical books and ten Tang musical books.

From the seven Sui musical books, to nine Sui musical books, to ten Tang musical books, they represent the first stage of the Tang music. This stage collects all kinds of excellent folk songs and dance essences, maintains the music and dance styles of different regions, and integrates the two dynasties' music culture, which makes the Tang music more prosperous.

The establishment of the sitting and standing geishas represents a new stage of the Tang music, that a large number of original dance music emerges. The Tang music constantly absorbs and learns from other ethnic music, and creates new musical works with more musical styles, represented by fast vigorous dance music and soft delicate dance music. A lot of small-scaled and entertaining dance music emerge, which adds more color to the music life of Tang dynasty.

The most exemplary achievement of Tang music is the large pieces of Yan music with rich application of instruments, dance genres and singing genres. The large pieces of Yan music is a large-scaled dance music with multiple structures, and the most representative work is the world famous "Feathered Rainbow Skirt”, which composed by Tang Xuanzong, and is a synthesis of Tang dance music. This work presents obvious Taoism color, grand scale, follows the rich experience of musicians, and reflects the performances ability of musicians to the greatest extent. It is recognized as the highest achievement in Tang dance music, and pushes the large pieces of Yan music to the peak. 


\section{The historical achievements and cultural values of the music institutes of the Tang Dynasty}

The music institutes of Tang Dynasty are very refined, which lays a solid foundation for the prosperity of the music culture.

The big music bureau the drum playing bureau belong to the Tai Chang temple. The big music bureau is equipped with rich senior musicians, who are responsible for the management and assessment of other musicians; it plays an important role in the management of national celebration, court etiquette and various worship activities. The drum playing bureau is carefully divided, that the drum department, Yubao department, cymbals department and horizontal blowing department all play an extremely important role, and shine in the honor of emperor and his relatives.

The royal school and pear orchard are directly administered by the court. The royal school is responsible for the instruction and management of the music performance inside the court, including Yan music, instrumental music, dance, singing, and Sanyue; the pear orchard is the dance music institute, which teaches the Faqu, and assembles the most outstanding talents in the country. It is a special dance and sing troupe selected from excellent musicians.

These higher music institutes adopt strict appraisal system and promotion system, which greatly improves the level of the Tang music and creates the prerequisite for the prosperity of Tang music.

\section{The historical achievements and cultural values of musicians in Tang Dynasty}

The Tang Dynasty is an era of music talents, that the development of music ranks top of Chinese music, and the famous musicians as well as their historical achievements are numerous.

Tang Xuanzong Li Longji is a famous emperor musician. He receives rigid and rich music education since childhood, and with his inborn talents, he cultivates multiple musical capabilities of composing, conducting and instrument playing. He presents a unique interest on flute and ancient drum playing, and creates some solo works of ancient drum, and entitles 92 pieces of ancient drum music. As the emperor of a dynasty, Tang Xuanzong's love of music directly stimulates the development of the Tang music, and his influence in the history of music is hard to ignore.

Li Guinian is a court artist elevated by Tang Xuanzong, and he is also a musician of pear orchard, being good at composing, singing, horn blowing and ancient drum playing. Many poets at that time depict the advanced skills of him in their poems. Li Guinian is a representative of the Tang musicians, and the "Wei Chuan Song" composed by him and his brothers makes very high historical and cultural achievements.

The most representative court singer in Tang Dynasty should be Yongxin, who is the daughter of musicians. She has superb singing skills, her voice is beautiful, and there is a strong touch in her performance, therefore she is recorded by many historical materials.

\section{The historical achievements and cultural value of Tang musical theory}

Twenty-eight tunes Yan music is also called the twenty-eight tunes folk music, which is firstly proposed by the Sui Dynasty musician Wan Baochang and Zheng Yi. The original version has eighty-four tunes, with twelve melodies as body and seven phase rotation as tune. But in the Tang version, only twenty-eight tones are used commonly, and is closely related to Qiuci music. The historical achievement is high.

Spectrum is the main means of music transmission, and the famous Guqin character-abbreviating spectrum is devised in the Tang Dynasty, which belongs to the finger spectrum. Th musician Cao Roujiangnan makes innovation and development of the character spectrum emerging in the Northern and Southern Dynasties. He abbreviates the strokes of characters and use notations to replace some literal description, then devises the Guqin character-abbreviating spectrum. Compared to character spectrum, the Guqin character-abbreviating spectrum presents superiority in recording spectrum.

The half-character spectrum is found in Dunhuang spectrum, using 20 notations to record music. It records the phonemes and techniques, with the Tang Pipa spectrum and Five Strings Pipa 
spectrum as the main body, and then it is developed into two branches of Song Dynasty folk spectrum and Guanse spectrum. The recorded works of this spectrum include "The Joy of Drinking a Toast", "West River Moon", "Changsha female introduction", "Spraying golden sand" and so on.

\section{The historical achievement and cultural value of Tang music}

The Tang Dynasty plays a decisive role in the history of Chinese ancient music culture, and is the peak period of Chinese music development. In this period, abundant excellent works of song and dance emerge, the musical instruments are reformed, the playing and singing skills are improved, the most important work of large pieces of music becomes world famous, the "Feathered Rainbow Skirt" gains both domestic and overseas reputation.

A large number of excellent musicians and dancers are able to devote their wisdom into the Tang music and dance art, leaving important musical achievements to the world. This is not separated from the political and economic basis established by Tang Xuanzong, as well as the enlightened ruling of him. Tang Xuanzong is proficient at musics and a variety of related skills, and gives great support to the development of Tang music; he assembles the musical talents in the country and cultivates them into even more excellent talents. He inherits the Wei Jin Southern and Northern Dynasties music culture, and absorbs the music culture of foreign countries, laying a foundation for music development in later periods, and making outstanding contributions to the music development in history.

\section{Conclusion}

Viewing the history, we can see the important position of Tang music in Chinese history, and feel regretted for the lost music. The late Tang ruler make their enjoyment unduely which leads to the ruin of court and the burning of musical civilization. This makes us realize the importance of cultural heritage more than ever.

Nowadays, the folk music culture in China is dying out. As a music scholar, I must attach importance to its inheritance, to exert my function and undertake my own duty.

\section{References}

[1] Discussion of the Tang Dynasty music institutes setting and function [J]. Cui Hairong. Popular literature (23) 2015.

[2] The influence of the Tang Dynasty court music culture on contemporary music education [J]. Chen Ruoqi. Journal of Mudanjiang Institute of education. 2015 (02)

[3] The study on music inheritance way of Tang musicians [J]. Feng Wenkai, Jia Qi. Yinshan Academic Journal (06) 2013.

[4] China ancient music history materials [M]. People's music publishing house, Yang Yinliu, 2001

[5] The influence of the Tang Dynasty court music culture on contemporary music education [J]. Chen Ruoqi. Journal of Mudanjiang Institute of education. 2015 (02) 